\title{
Metaspace futures
}

Paul Sermon, University of Brighton

Claire McAndrew, University College London

\author{
Keywords \\ informality \\ metaspace \\ telematic \\ resettlement communities \\ urbanism \\ speculative futures \\ architecture \\ distributed authorship
}

In Roy Ascott's 1983 La Plissure du Texte (The Pleating of the Text) (Ascott and Shanken 2003), we saw the first flicker of digitally enabled, distributed authorship. Collapsing time and space through interactivity produced a layering of semantics that translated into unimagined, new narratives. Metaspace Futures documents our use of distributed authorship in telematic practice, to create a visual and embodied commentary on increasingly compact living spaces.

Supported by the Arts and Humanities Research Council, the project $3 \times 4$ exploring metaspace platforms for inclusive future cities builds on the established creative practice of interactive media artist Paul Sermon by merging a $3 \times 4$ metre room installation at Khōj International Artists' Association in Delhi with an identical space at the Southbank Centre in London. These dimensions reflect the plot size provided in some resettlement colonies such as Savda Ghevda in Delhi - a government initiative that relocates people from informal settlements within the city, commonly known as slums, to vacant land usually on the periphery. 
The issue of living space is not just exclusive to metropolises of the global south. In cities such as London, we see an increasing reduction in the amount of space many people have when they first start out in the city, as 'affordability' is simply translated into 'smaller'. Through telematic installation, audiences in the two cities at Khōj International Artists' Association in Delhi and the Southbank Centre in London were brought into an altogether new kind of $3 \times 4$ 'metaspace' and embodied dialogue on living spaces and practices.

Using a live telematic videoconference connection, the installation functioned between two geographically distant audiences located in a $3 \times 4$ metre green-box in London and an equivalent blue-box in Delhi. Public audiences in these spaces were captured on camera and brought together through a system of live chroma-keying that superimposed them on a computer-generated background. This live feed was then streamed to video screens in both locations. In this telepresent space, the merged audiences encountered a series of digital scenes they now coexist within. These background scenes were created by online participants and directly referenced their combined social setting, ranging from informal settlement dwellings and Delhi environments to contemporary compact interior designs and imagined worlds. Downloading, modifying and re-uploading the open-source contributions of others further defined the process of distributed authorship.

Presented during UnBox Festival in Delhi from 12 to 14 December 2014 for six hours per day, $3 \times 4$ at Khōj International Artists' Association saw over 500 visitors from the Khirkee Extension community, with many return visits to engage in this converged global experience. Its success led to the presentation of $3 \times 4$ between Royal Festival Hall in London and India Habitat Centre in Delhi during May 2015 to coincide with Southbank Centre's Alchemy and Web We Want Festivals receiving in excess of 10,000 visitors. As an alternative to dominant social networking platforms, it provided an open provocation on globally distributed authorship: connecting ideas, provocations and imaginaries through a visual dialogue that was extended through embodied experience.

The installation $3 \times 4$ is a temporal and spatial timecode; reduced to its ephemeral elements it consists of eighteen hours of memories and reflections in the minds and 
collective narratives of those who participated in it, played out over three days on 12 14 December 2014 from 10:00 GMT / 15:30 IST to 16:00 GMT / 21:30 IST daily. Ultimately what remains as its legacy is a story told in and between two cities consisting of human encounters and events that unfolded in a state of flux between London and Delhi. Whilst every effort was made to document this transitory happening through photographs and video footage the single most important recording was from the line out video feed; the final composited or chroma-keyed image of the audience participants displayed within the installation itself. When watching this recording we are taking up the position of the persons within it; we are looking directly at the very same image that caused the effect we are now contemplating for ourselves.

From beginning to end, the entire recording represents a 1080-minute data stream upon which we view the narrative through this 'two-way mirror' - such as when three ladies in Delhi enter with two babies greeted by participants in London eager to hold and play with them, who appear to be mesmerized by this Lacanian moment of realization as the babies stare into the screen (mirror) (Lacan [1966] 1989). As a coauthoring of built and imagined landscapes it offered critical visual commentary on living spaces, racial segregation, informality, underground culture and contemplative fantasies. Occupying a part-demolished building via $3 \times 4$ took the matters of informal architecture, contested space and merciless destruction to a global audience. Not just imaginings, $3 \times 4$ also morphed into a playground of spontaneous and undirected play. Children, for whom the street and the objects it contains form a recreational landscape, shifted their space of play to this metaspace. The data stream contains memorable moments, such as when a young boy in Delhi enters the space and initially waves to participants in London, staying for over an hour perfecting his interactions and gestures as he invents and plays new games. 'Playing the city' in an embodied manner can extend these visual narratives, shaping and layering them in new and unexpected ways.

The creative team behind this project were first brought together at the National Institute of Design in Ahmedabad for UnBox LABS in March 2014 to discuss, scope and ideate on the theme of Future Cities. This included selected AHRC UnBox Fellows; Professor Paul Sermon at University of Brighton and Dr Claire McAndrew 
at UCL's Institute for Digital Innovation in the Built Environment, The Bartlett and creative partners from India; Swati Janu at microHome Solutions City Lab Delhi and Bangalore-based photographer Vivek Muthuramalingam. Our interdisciplinary range of subject specialisms and practices were first brought together and explored in a scoping project that culminated in the development of a prototype video installation, consisting of a $3 \times 4$ metre muslin-covered bamboo structure exhibited at UnBox LABS. This installation incorporated video projections of images and quotes sourced directly from informal settlements and their inhabitants, focusing on the role of networked technologies within these communities.

In the context of informal settlements in megacities of the global south, the $3 \times 4$ installation provided many public participants with their first encounter of a networked platform. Through this unique engagement public audiences acquired new knowledge through distributed authorship and lived experiences of possible visions for future living spaces. These first time encounters and experiences can be used by the participants to influence future projects, define methods for using this new knowledge to inform themselves, who in turn tell their family, friends and colleagues of this new experience, motivating others to engage in similar experiences in future projects. The intention of this legacy is to inform a critical public community that impact on future network protocols and the design of living spaces appropriate to the needs and requirements of future cities. At the same time it seeks to identify its relevance in the global north. The dialogue between Delhi and London is a critical pathway in connecting communities through a co-authored dialogue on informality in the global south and its symbiotic relation to living spaces in the global north.

$3 \times 4$ comes at a time where cities are reaching breaking point of swelling populations, where lack of affordability limits opportunities to participate in cities. Distributed authorship in telematic practice can bring built and imagined narratives closer together, creating new visual and embodied commentaries about how we occupy space in cities. It is from this search for alternative narratives that value the self-made and temporary nature of informality, alongside the unfolding hybrid of physical place and digital space that cities of the future will arise. 


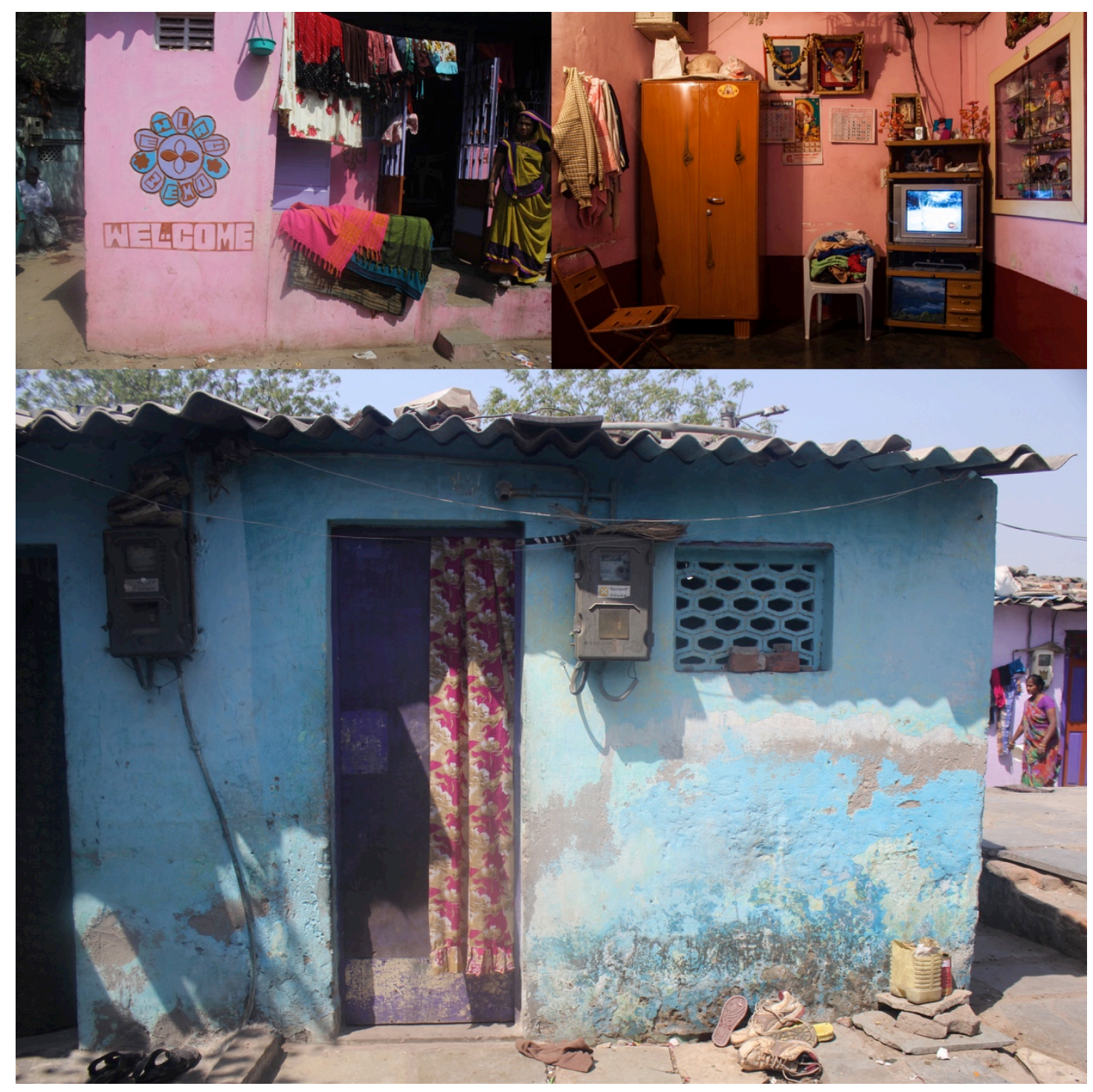

Figure 1: Ethnographic research (part I) in Ahmedabad during UnBox LABS, March 2014. 


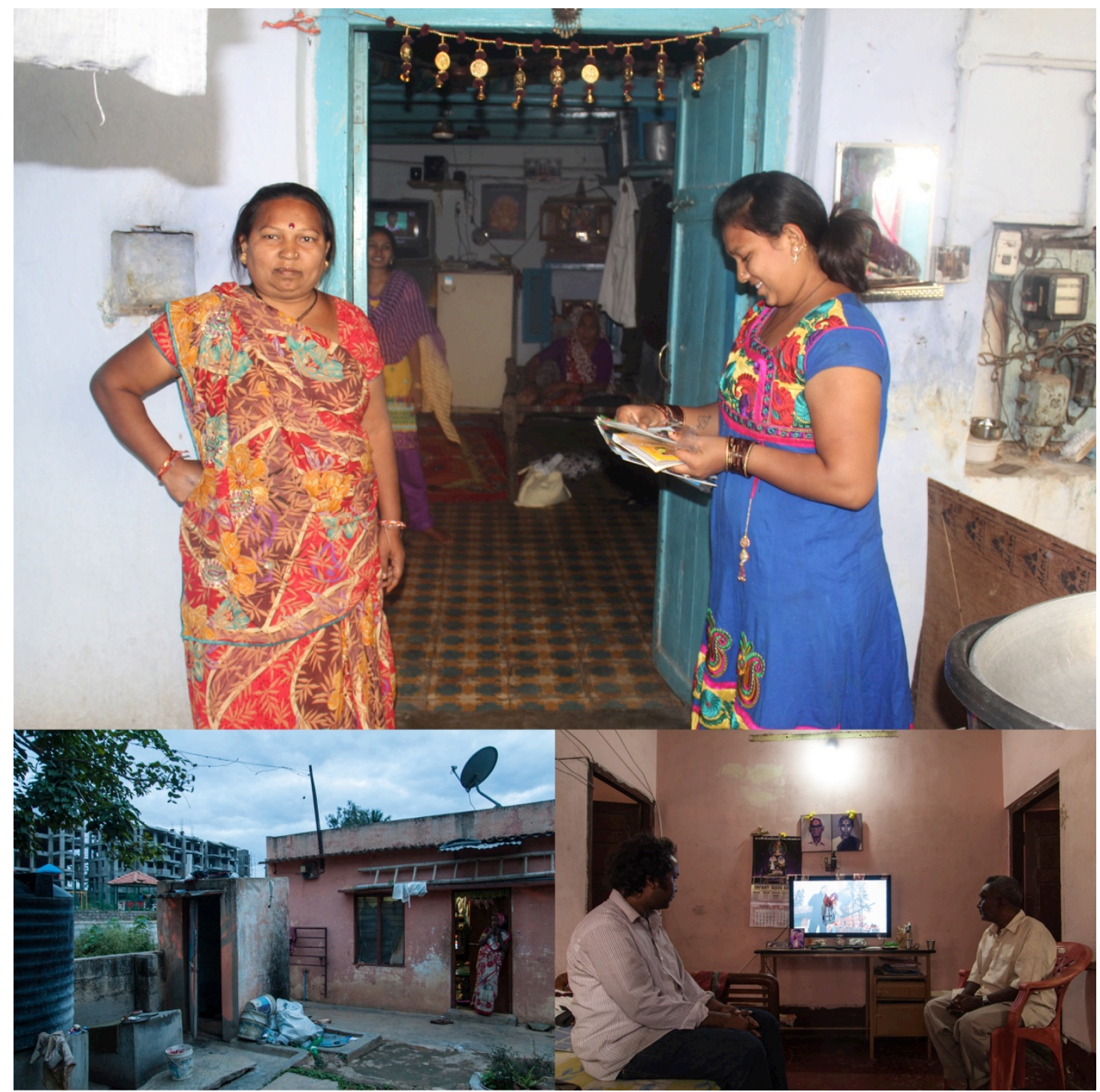

Figure 2: Ethnographic research (part II) in Ahmedabad during UnBox LABS, March 2014. 


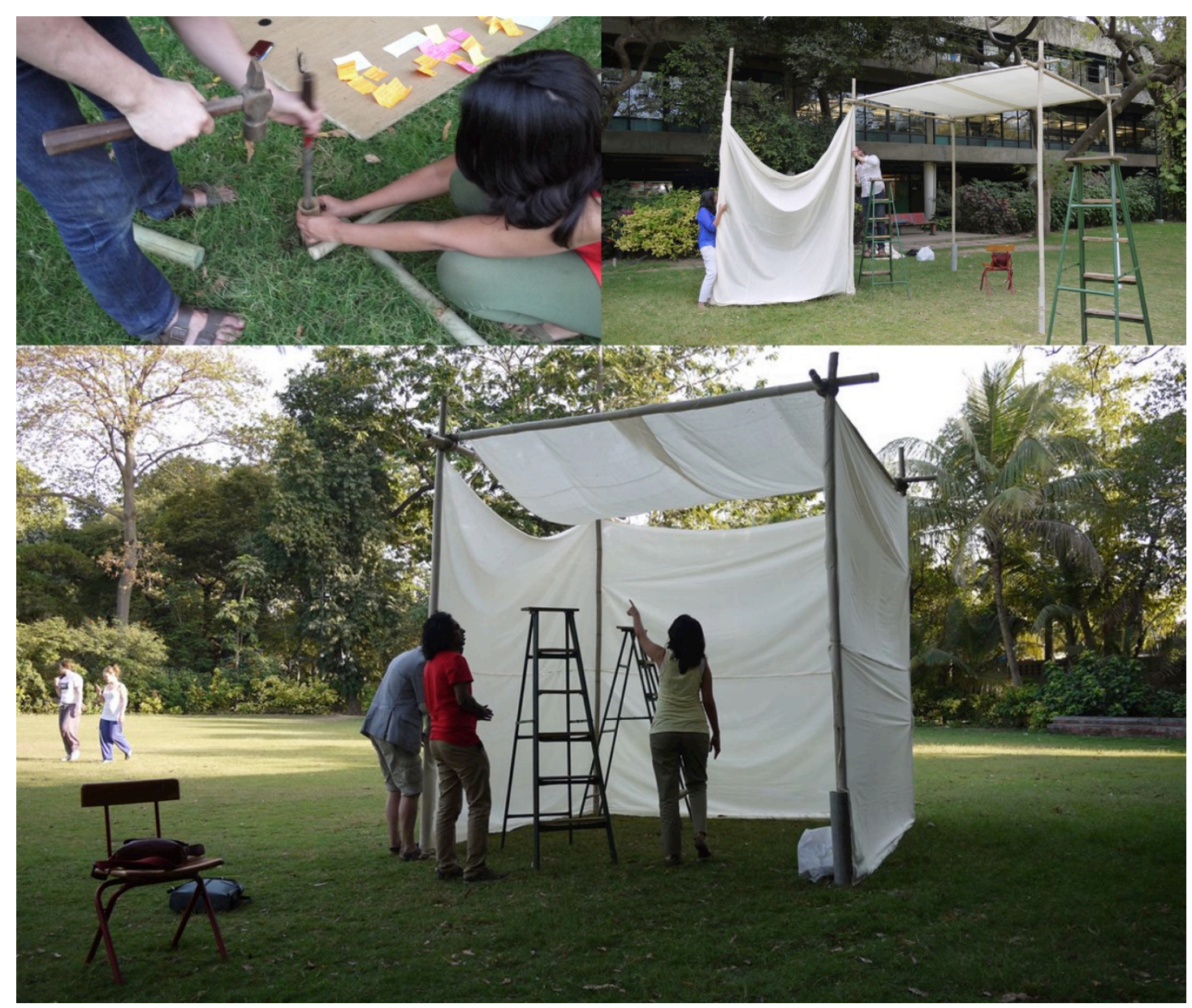

Figure 3: Construction of 3×4 metre prototype during UnBox LABS, March 2014. 


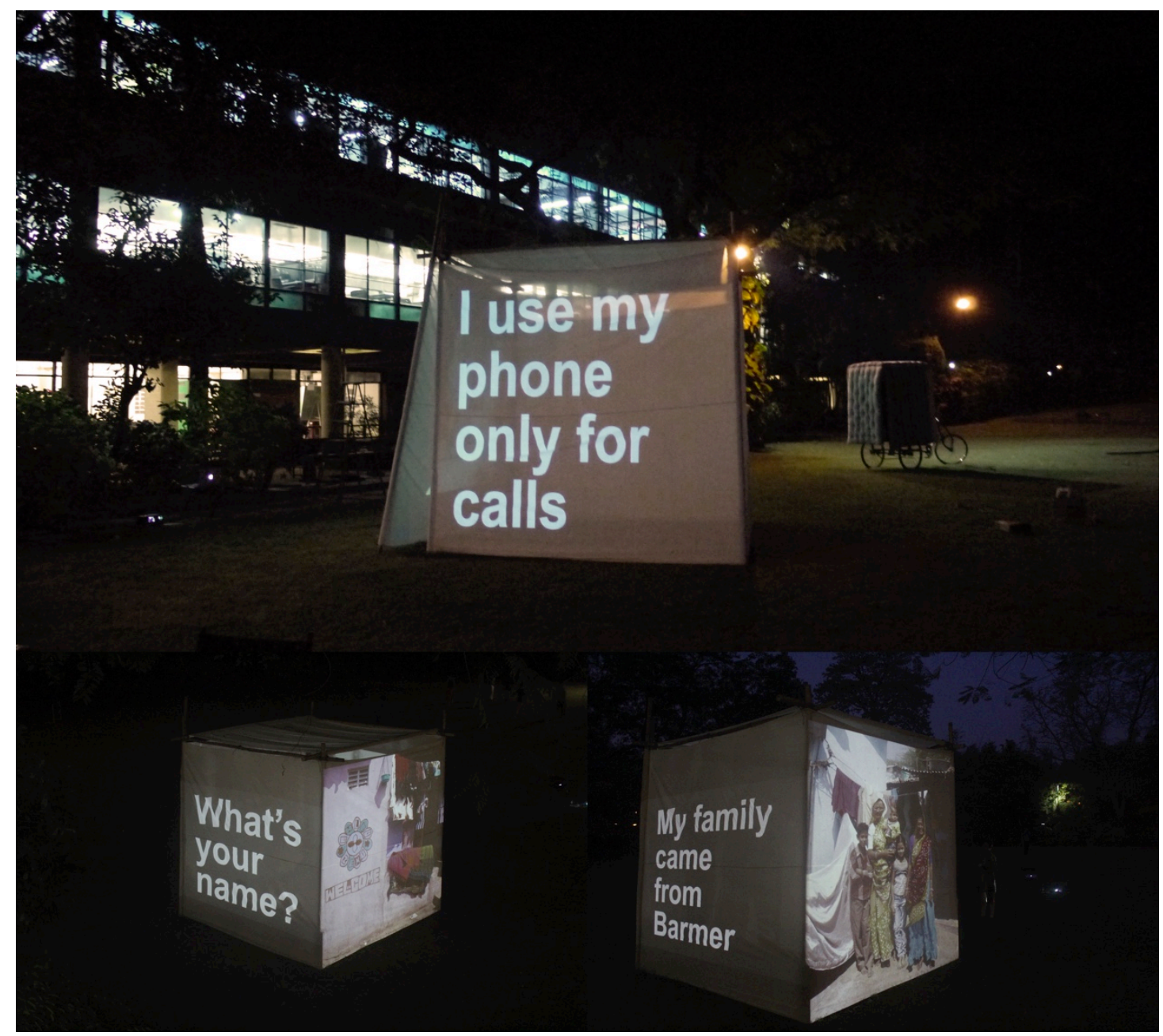

Figure 4: Back projection on $3 \times 4$ metre prototype of comments and images gathered during ethnographic research for UnBox LABS exhibition, March 2014. 


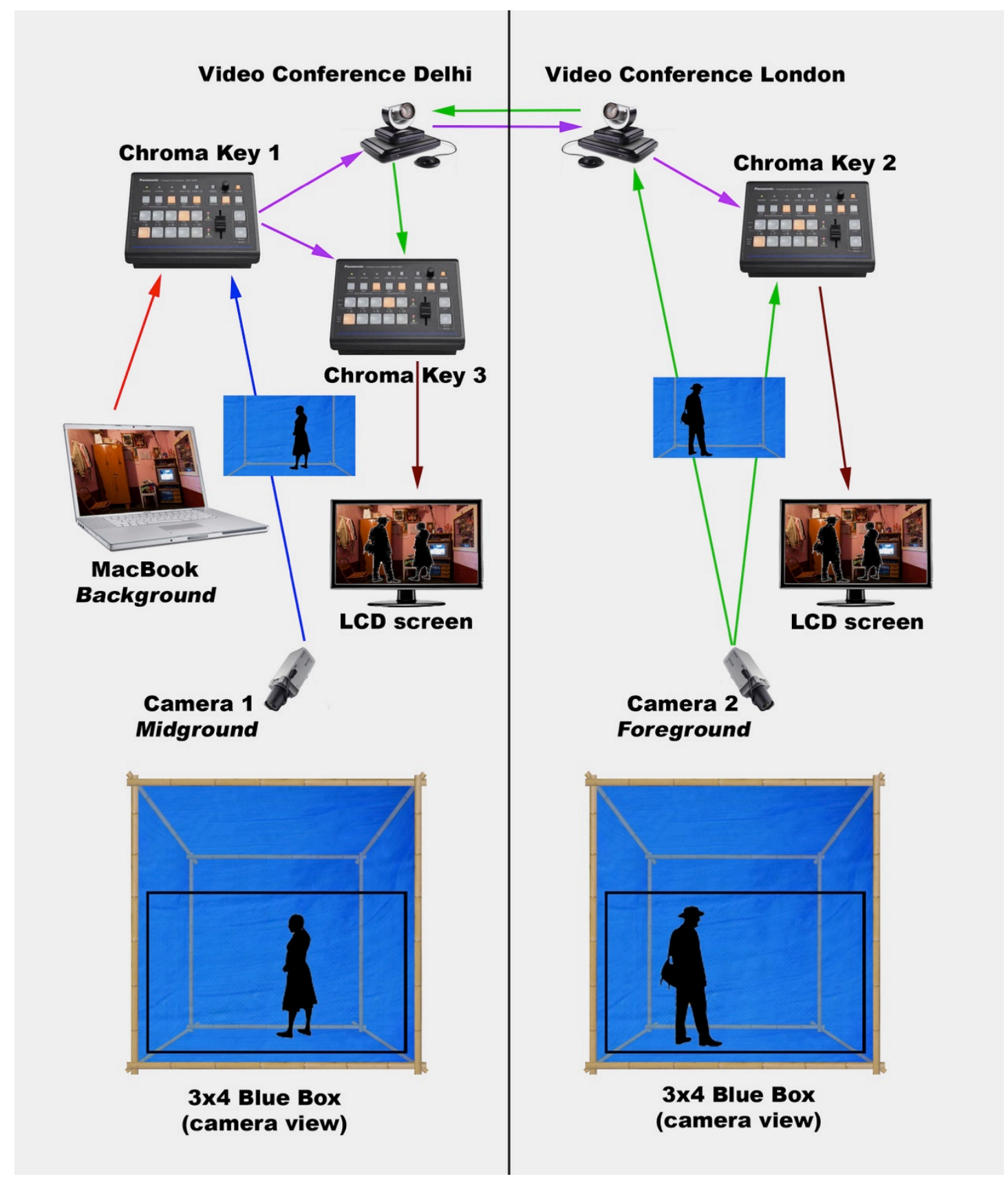

Figure 5: Telematic flow diagram, detailing videoconference connection between Delhi and London and the live chroma-keying process, November 2014. 
FOREGROUND

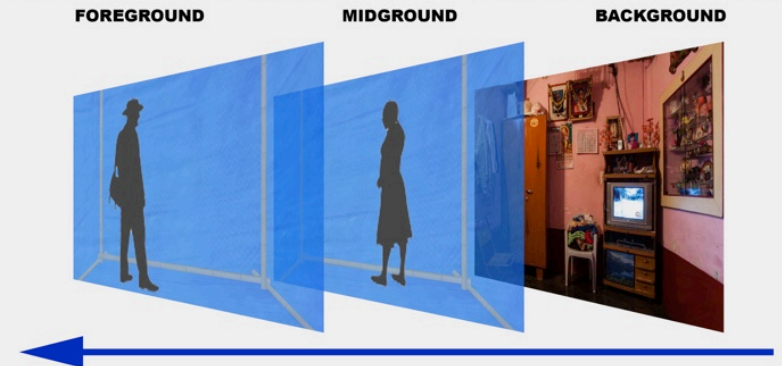

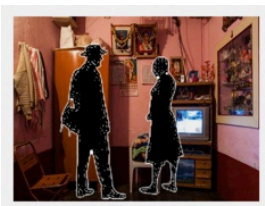

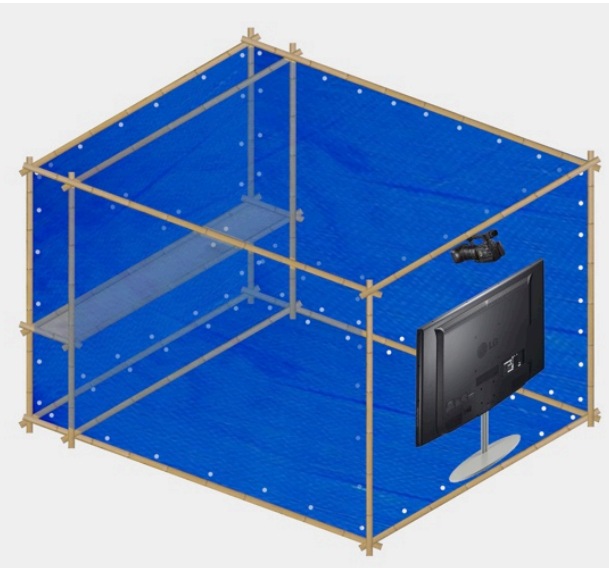

Figure 6: Chroma-key layering process of live video streams (left) and $3 \times 4$ installation construction model (right), November 2014.

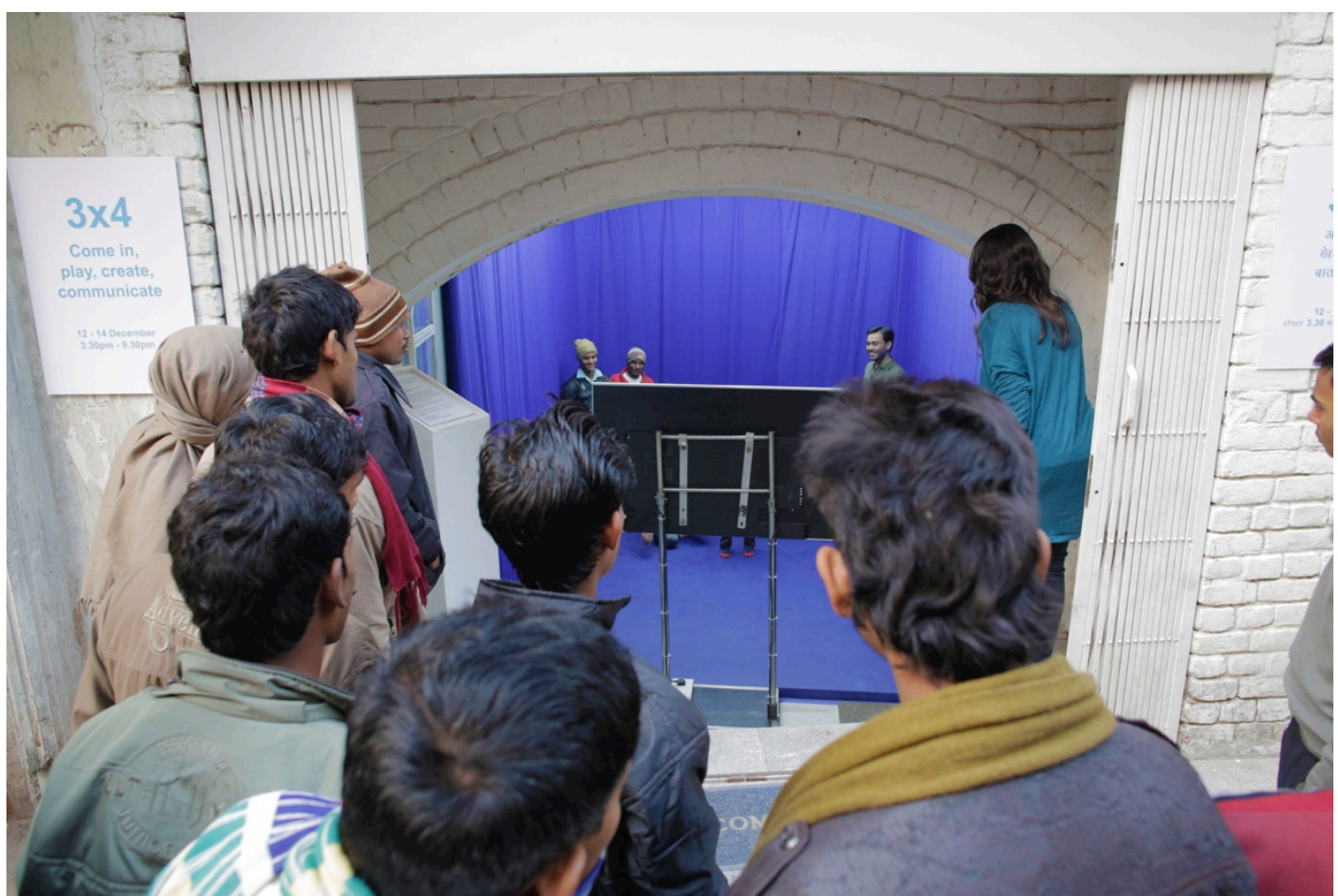

Figure 7: Street entrance into $3 \times 4$ installation at Khōj International Artists'

Association in Khirkee Extension New Delhi, 12-14 December 2014. 


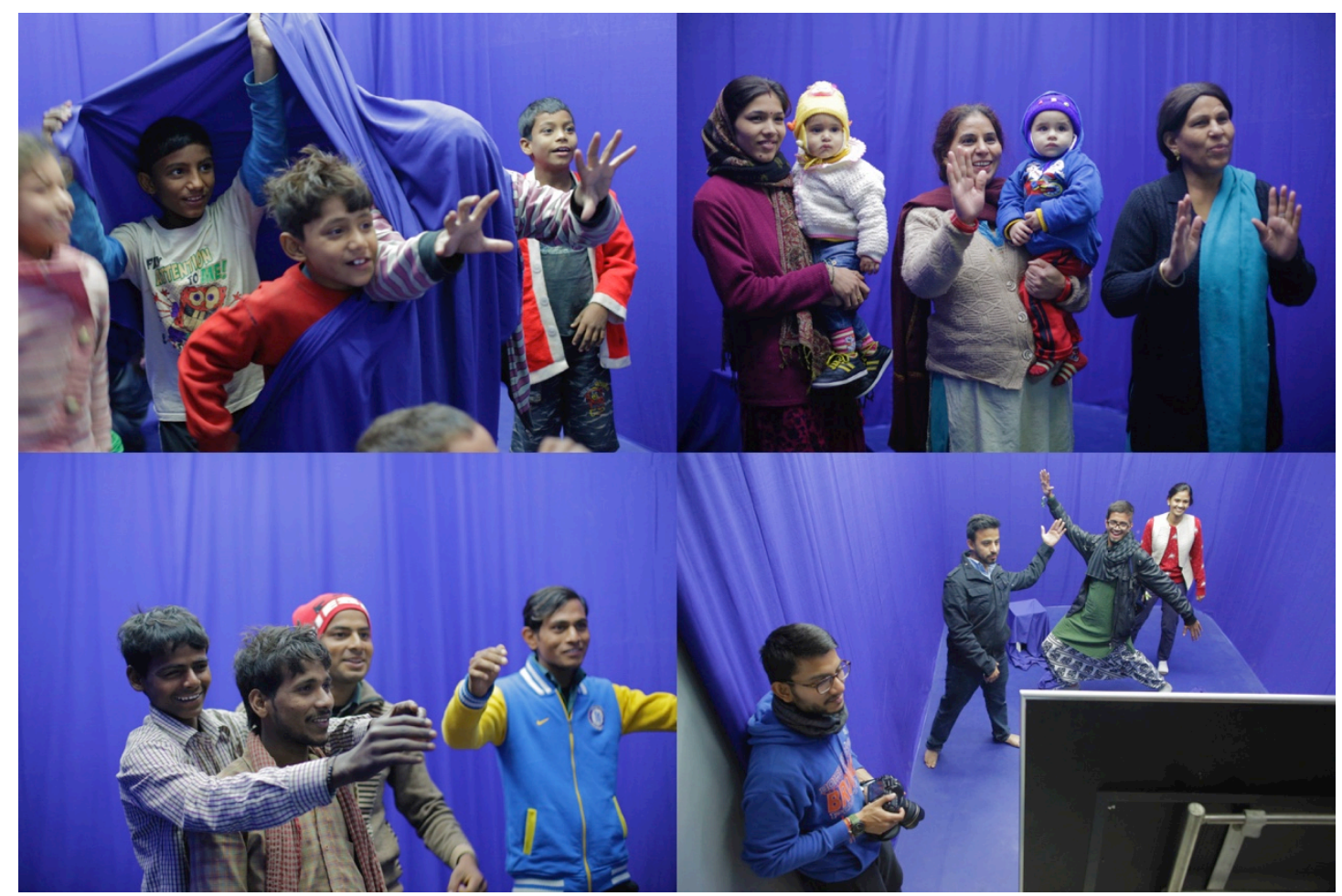

Figure 8: Public participants from Khirkee Extension, New Delhi in $3 \times 4$ installation at Khōj International Artists' Association - embodied interactions with telepresent participants from Festival Village, Southbank Centre London, December 2014.

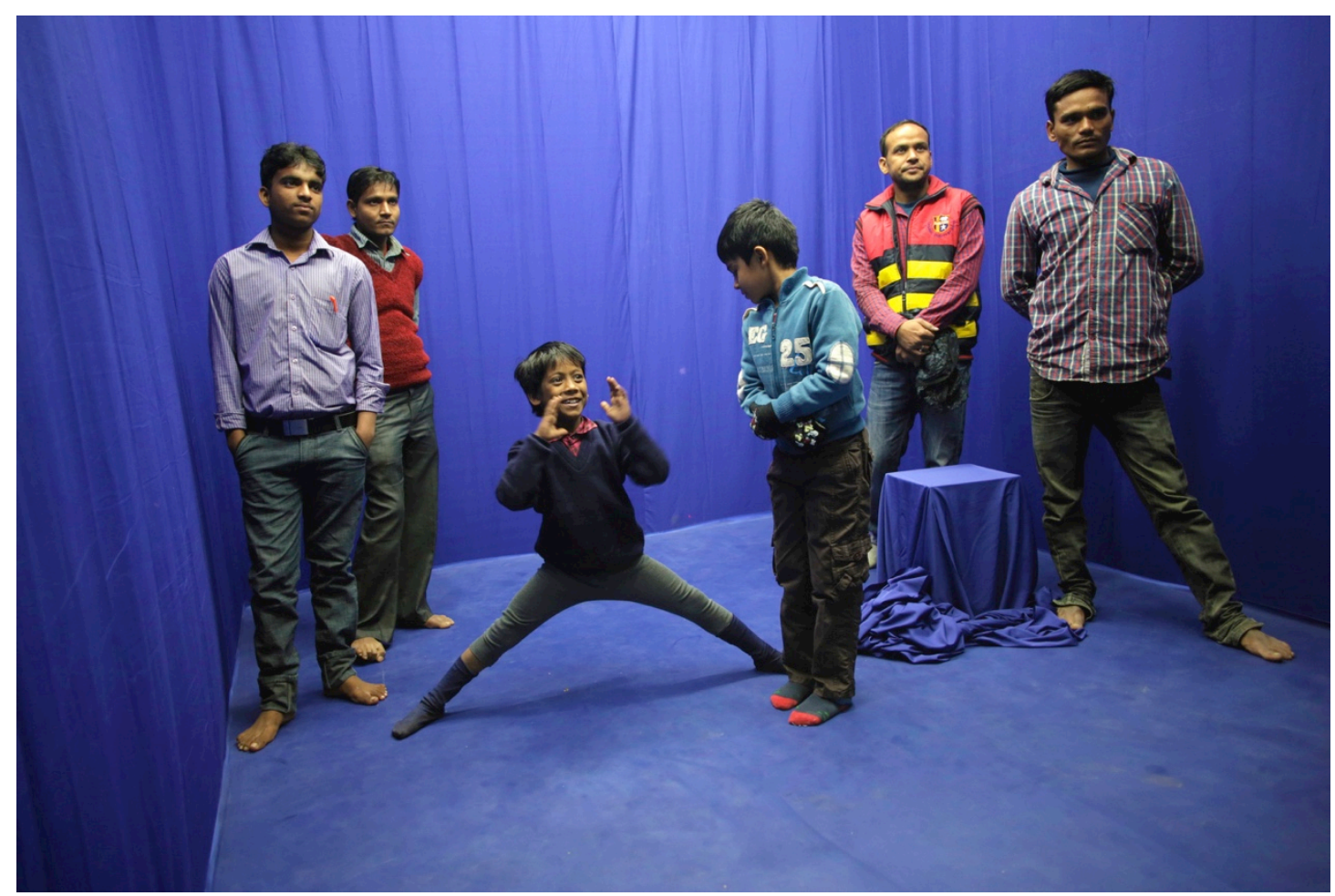

Figure 9: Public participants from Khirkee Extension, New Delhi - playing and interacting in $3 \times 4$ installation at Khōj International Artists' Association, December 2014. 


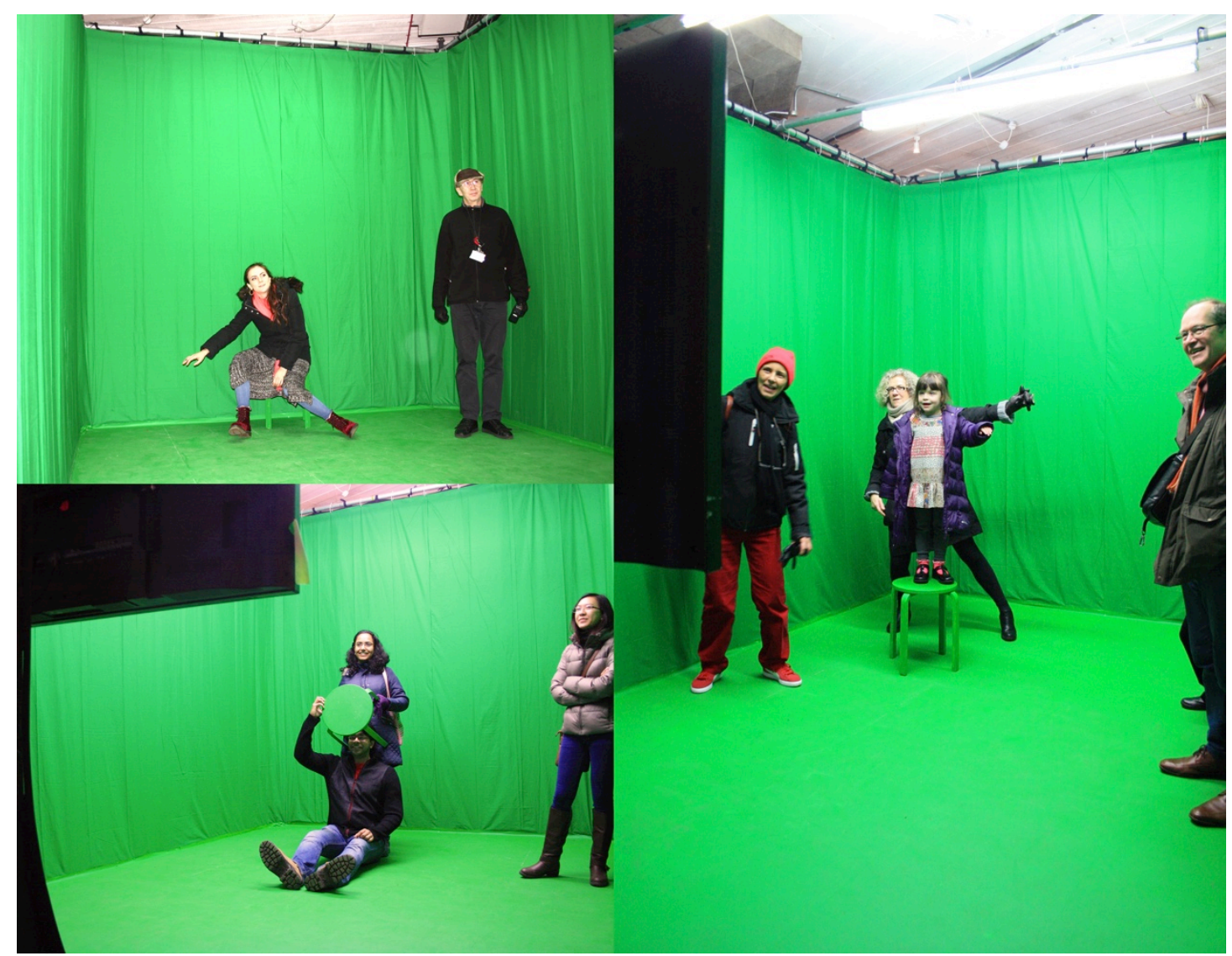

Figure 10: Public participants in $3 \times 4$ installation at the Southbank Centre's Festival Village - performing and constructing new narratives with public audiences at Khōj International Artists’ Association, New Delhi, December 2014.

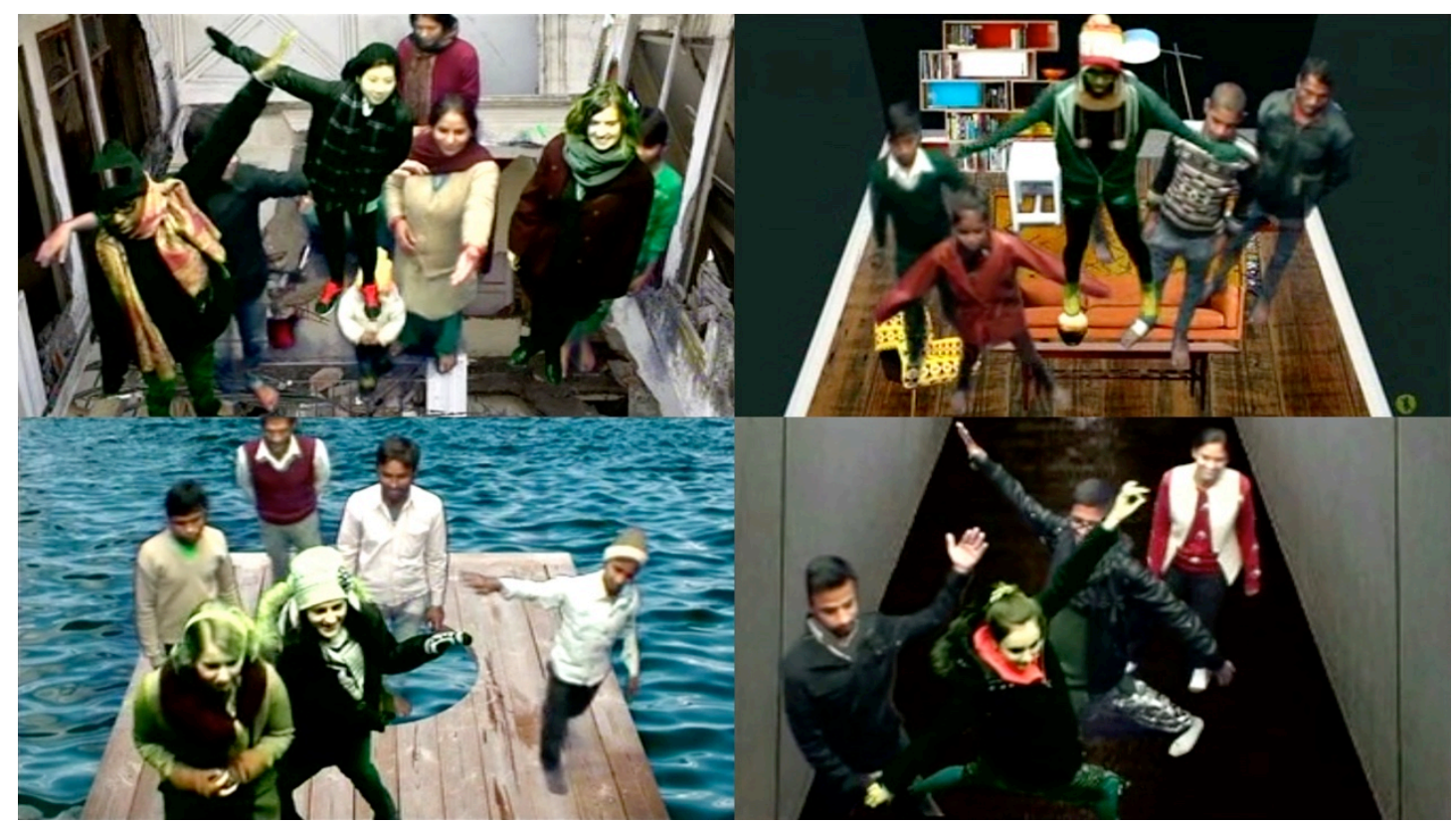

Figure 11: Line out video feed of the final chroma-keyed video image of participants in Delhi and London - superimposed on computer-generated backgrounds created by online participants, 12-14 December 2014. 


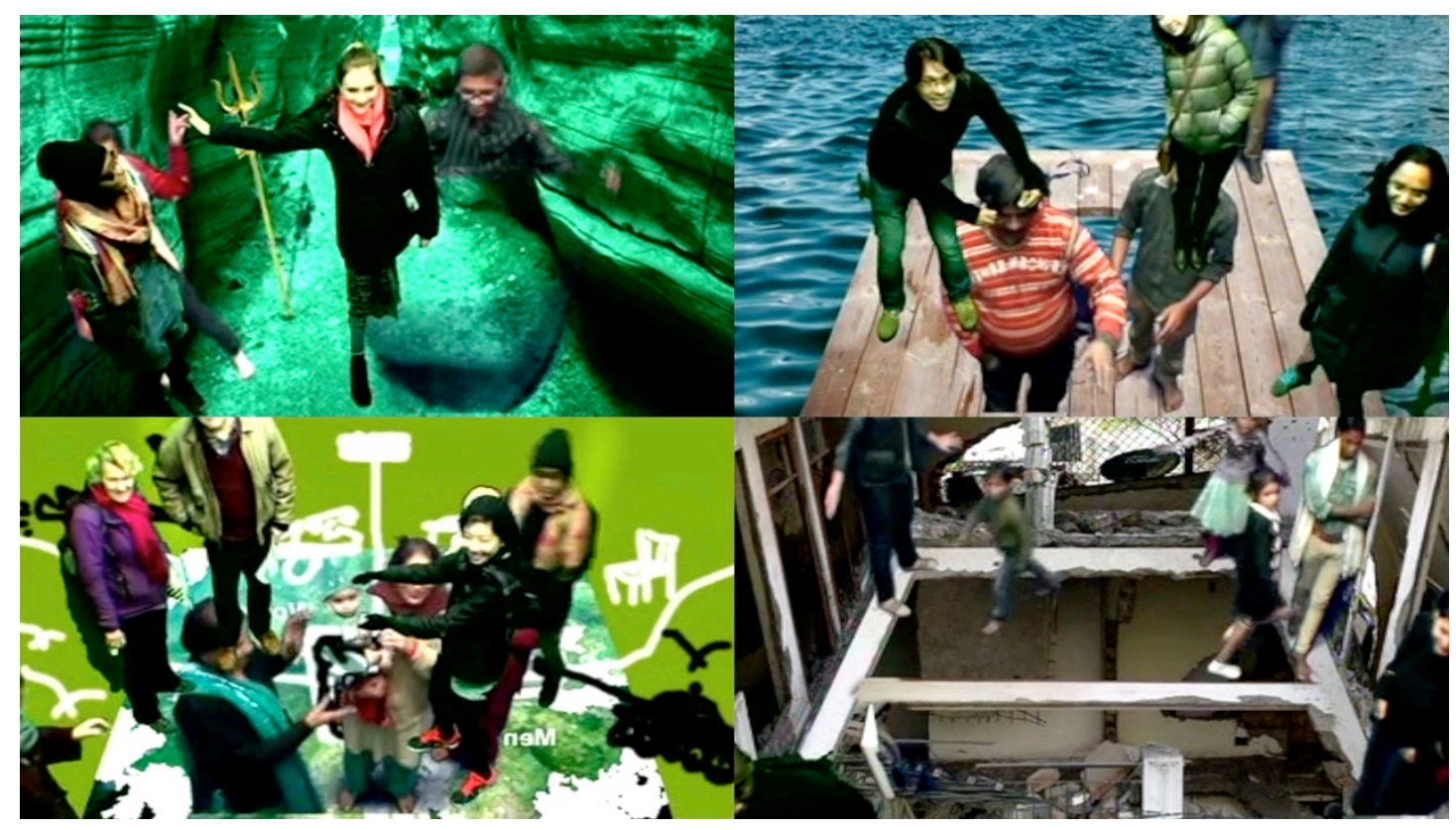

Figure 12: Line out video feed of the final chroma-keyed image of participants in

Delhi and London displayed live within both $3 \times 4$ installations simultaneously, 12-14

December 2014.

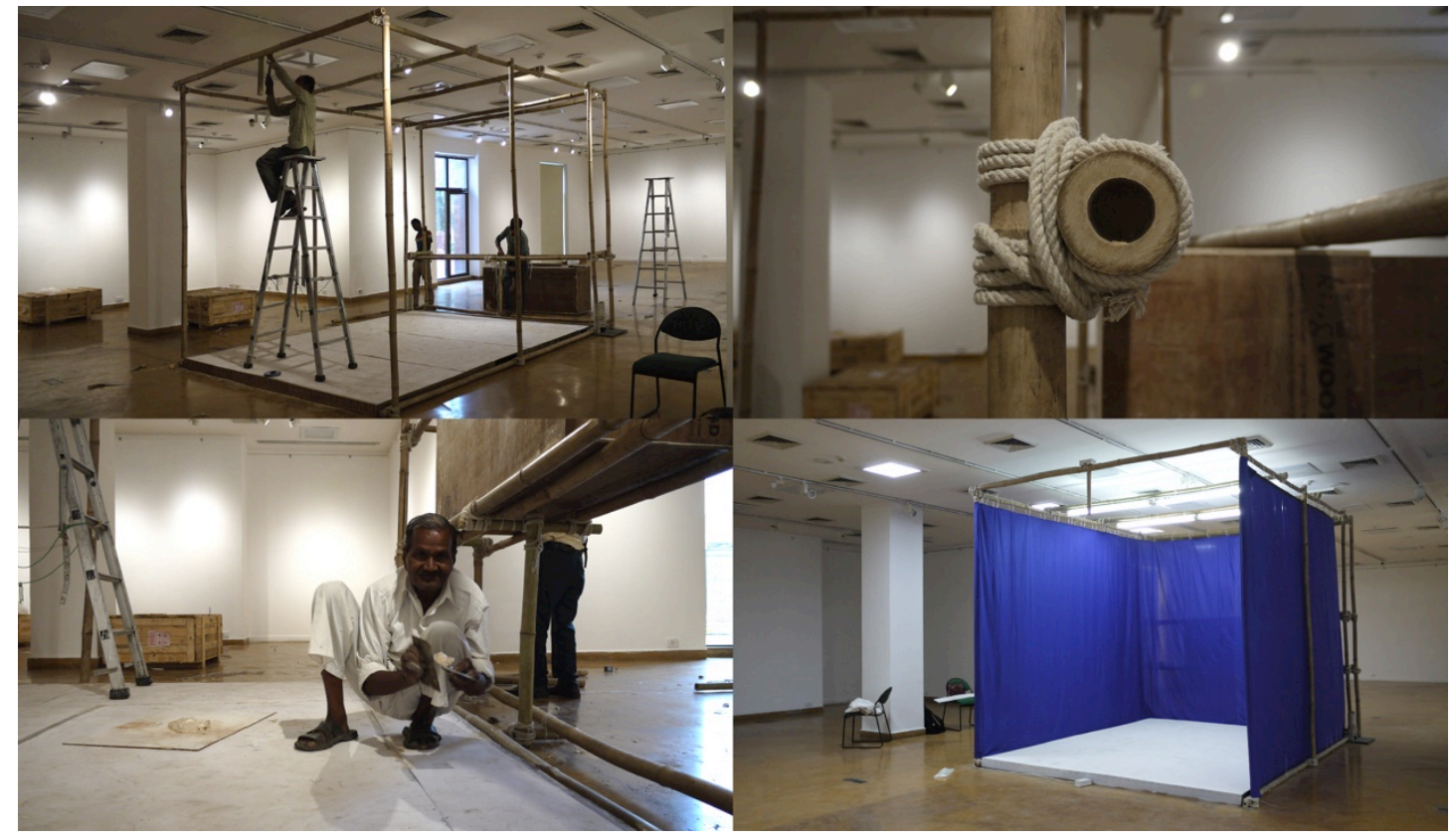

Figure 13: Construction of $3 \times 4$ installation at India Habitat Centre Art Gallery, New Delhi - linked to the Royal Festival Hall in London for the Southbank Centre's Alchemy and Web We Want Festivals, 15-31 May 2015. 


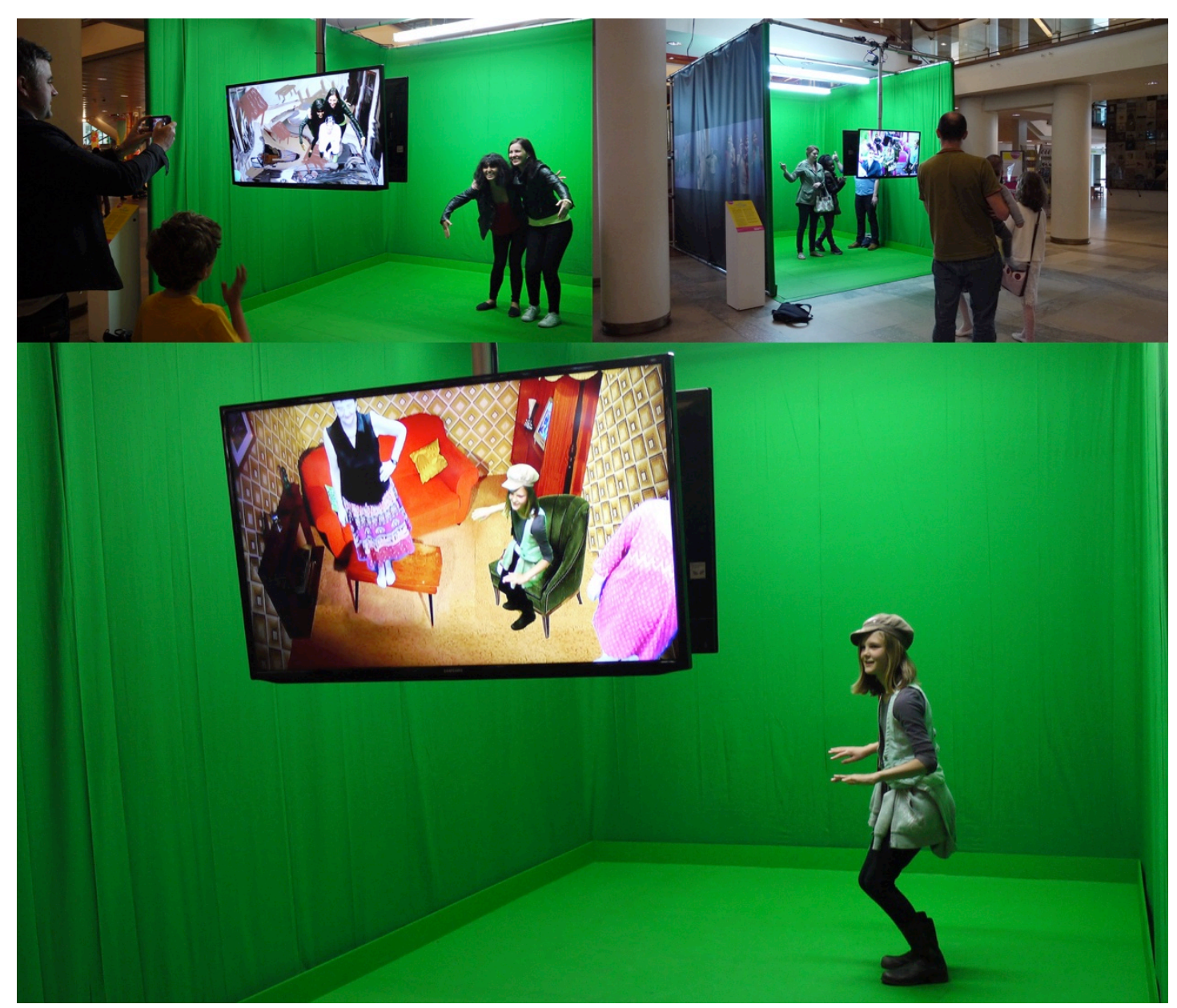

Figure 14: Public participants in $3 \times 4$ installation at the Southbank Centre's Royal Festival Hall for the Alchemy and Web We Want Festivals, connected with a public audience at the India Habitat Centre, New Delhi, May 2015.

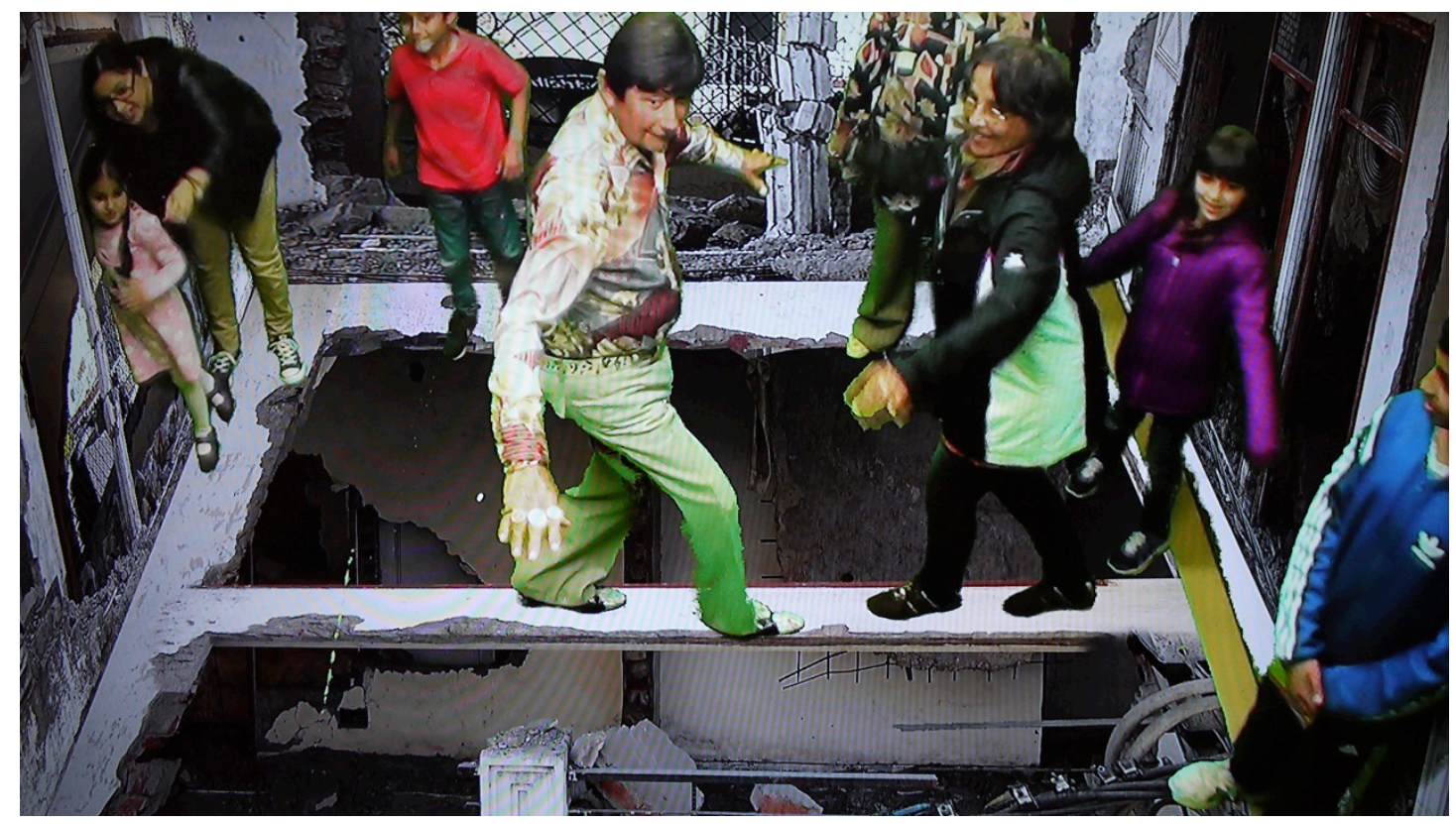

Figure 15: Line out video feed of the final chroma-keyed video image of participants 
in Delhi and London - superimposed on computer-generated backgrounds created by online participants, May 2015.

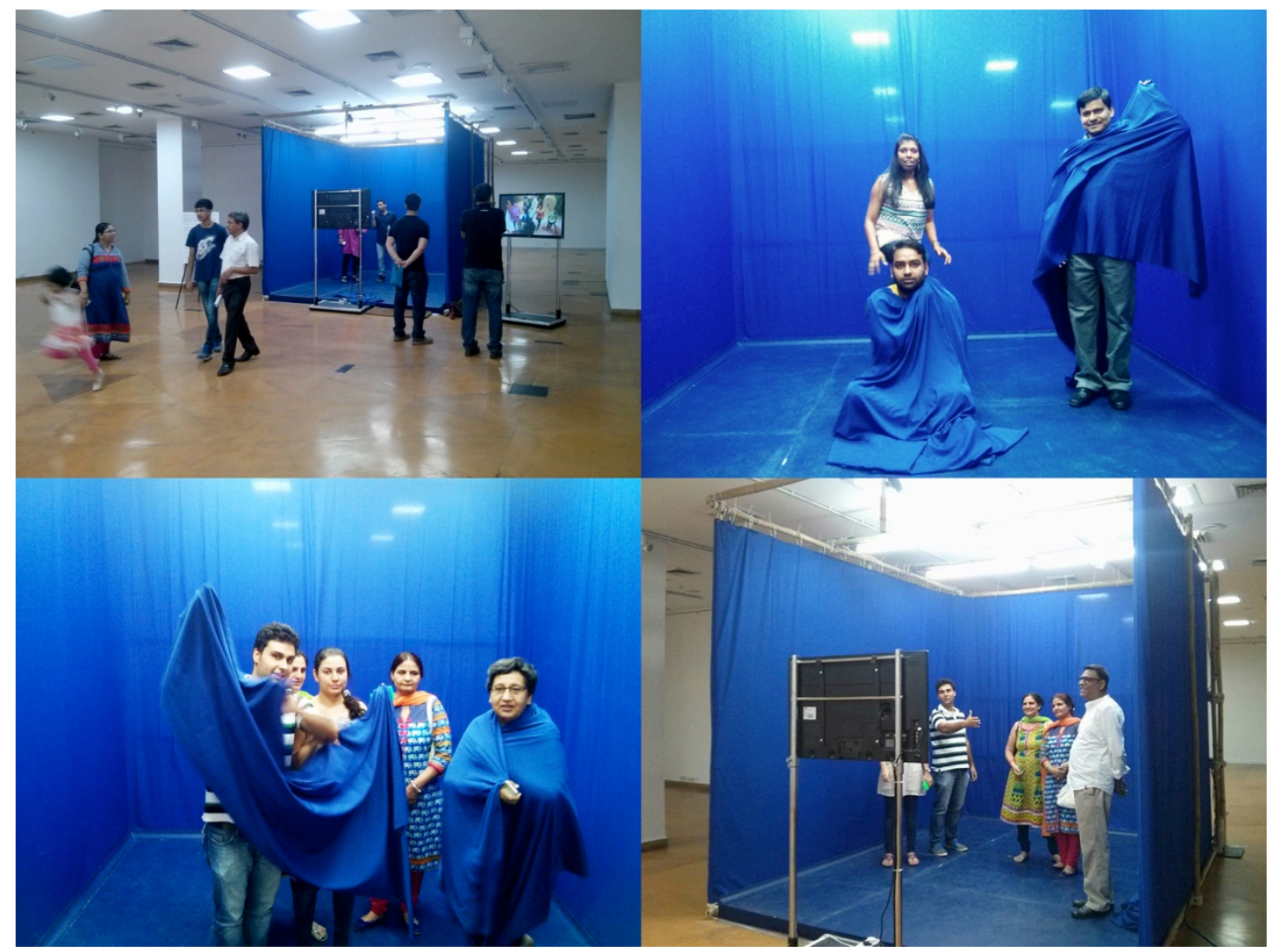

Figure 16: Public participants in $3 \times 4$ installation at the India Habitat Centre Art Gallery, New Delhi - connected with a public audience at the Southbank Centre's Royal Festival Hall in London for the Alchemy and Web We Want Festivals, 15-31 May 2015.

Project website: http://www.3x4m.org

\section{References}

Ascott, R. and Shanken, E. (eds) (2003), Telematic Embrace: Visionary Theories of Art, Technology, and Consciousness, Berkeley, CA: University of California Press.

Lacan, J. ([1966] 1989), 'The Mirror Stage as Formative of the Function of the $I$ as Revealed in Psychoanalytic Experience', in Écrits/Écrits: A Selection, Paris/London: Éditions du Seuil/Routledge, pp. 1-8.

\section{Contributor details}


Paul Sermon is Professor of Visual Communication at the University of Brighton. He has worked for over twenty years as an active academic researcher and creative practitioner, primarily in the field of telematic arts. Having worked under the visionary cybernetic artist Professor Roy Ascott as an undergraduate Fine Art student, Paul Sermon went on to establish himself as a leading pioneer of interactive media art, winning the prestigious Prix Ars Electronica Golden Nica in Linz, Austria, shortly after completing his MFA at the University of Reading in 1991. An accolade that took Paul to Finland in the early 1990s to develop one of the most groundbreaking works of his career Telematic Dreaming in 1992.

Contact: Paul Sermon, College of Arts and Humanities, University of Brighton, Grand Parade, Brighton BN2 0JY, UK.

E-mail: p.sermon@brighton.ac.uk

Web address: http://www.paulsermon.org

Dr Claire McAndrew is a Senior Research Associate at The Bartlett and Director of Research at UCL's Institute for Digital Innovation in the Built Environment. She joined The Bartlett in 2011, receiving her Chartered Psychologist status the same year. Combining social science insight with design-led thinking, she is interested in the possibilities of design and digital innovation within the built environment for transformative social and cultural effect. Her research focuses on the contexts of human wellbeing, security and resilience, workplaces and speculative digital futures.

Contact: Claire McAndrew, UCL Institute for Digital Innovation in the Built Environment, The Bartlett, University College London, 132 Hampstead Road, London NW1 2BX, UK.

E-mail: c.mcandrew@ucl.ac.uk

Paul Sermon and Claire McAndrew have asserted their right under the Copyright, Designs and Patents Act, 1988, to be identified as the authors of this work in the format that was submitted to Intellect Ltd.

Photographs and diagrams by Paul Sermon, Claire McAndrew, Swati Janu, Vivek Muthuramalingam and Melanie Issaka. 